\title{
Inducible resistance to herbivory in Fucus vesiculosus - duration, spreading and variation with nutrient availability
}

\author{
Anne Hemmi*, Tuija Honkanen, Veijo Jormalainen \\ Section of Ecology, Department of Biology, University of Turku, 20014 Turku, Finland
}

\begin{abstract}
Inducible resistance in plants is a defense strategy for avoiding the negative consequences of herbivory on plant fitness. Since resistance is costly, the induction of resistance may depend on resource availability. Resource-based plant-herbivore hypotheses predict that the cost of producing carbon-based defensive metabolites will be higher when an excess of nutrients is available for growth. We tested experimentally the effect of nutrient availability on the occurrence, duration and within-alga spread of inducible resistance in the brown alga Fucus vesiculosus L. Based on feeding preference bioassays using the herbivore Idotea baltica (Pallas), simulated grazing of $F$. vesiculosus caused a clear, rapid, induced resistance that disappeared after 10 to $38 \mathrm{~d}$. Furthermore, the induction of resistance does not spread to neighboring fronds or to growing tips above the point of simulated grazing. Induced resistance against isopod grazing, however, was not explained by increased production of phlorotannins, despite their putative role in the defense against herbivory. Phlorotannin production responded most strongly to nutrient enhancement, which reduced the phlorotannin concentration of the alga. Nutrient enhancement, however, did not affect the induction of resistance. The occurrence of induced resistance together with the lack of correlation between the phlorotannin concentration and the food preferences of herbivores imply that $I$. baltica is not deterred by the total quantity of phlorotannins; there may, however, be other, as yet unknown, rapidly inducing substances in F. vesiculosus that are capable of functioning as feeding deterrents to isopod grazers. Resistance may also arise as a side-effect of substances with a functional role, for instance in wound-healing processes. The localized nature and short duration of such deterrence imply that it may be inefficient as a general defense against herbivory, but may benefit the alga by dispersing future damage within the individual and avoiding the breakage of whole fronds.
\end{abstract}

KEY WORDS: Fucus vesiculosus - Inducible resistance - Nutrients - Eutrophication · Herbivory · Chemical defense $\cdot$ Phlorotannins $\cdot$ Plant-herbivore interactions

Resale or republication not permitted without written consent of the publisher

\section{INTRODUCTION}

The production of secondary metabolites is often suggested to protect vascular plants and algae against herbivory. Chemical defenses occur on either a constitutive or an inducible basis (inducible defense hypothesis), their mutual profitability to the plant depending on a number of environmental, biochemical and lifehistory parameters (Karban \& Myers 1989). Inducible defenses are considered more profitable than constitutive ones when a plant is relatively long-lived (Karban
\& Baldwin 1997), the presence of herbivores is variable and unpredictable (Harvell 1990, Clark \& Harvell 1992, Herms \& Mattson 1992, Hay 1996), defensive secondary chemicals are costly to produce (Rhoades 1979), and defenses are quantitative (Karban et al. 1997). Attack by herbivores may induce resistance in the plant either quite rapidly (Carroll \& Hoffman 1980) or after a delay, and the resistance may either fade quite rapidly or be sustained for a longer period of time (Haukioja 1982, Yates \& Peckol 1993). Moreover, the costs of resistance for the plant may vary according to 
the availability of resources (Karban \& Myers 1989, Herms \& Mattson 1992).

The occurrence of chemical resistance induced by true or artificial herbivory has been widely studied and documented in a variety of terrestrial plants (reviewed in Karban \& Baldwin 1997, Tollrian \& Harvell 1999, Koricheva 2002). Despite its ecological relevance, however, only a few studies have explored the occurrence of induced chemical resistance in perennial seaweeds, and knowledge on the spread and duration of induced responses is almost lacking (but see Van Alstyne 1988, Peckol et al. 1996). The concentration of phlorotannins in brown seaweeds has been widely used to indicate the level of chemical resistance of a plant to herbivory. Phlorotannins are phenolic compounds specific to brown algae. In addition to their putative role in defenses against herbivory, other suggested ecological functions of phlorotannins include acting as a UV screen (Pavia et al. 1997) or as antimicrobial, antipathogenic or antifouling substances (Pawlik 1992, Schmitt et al. 1995, Targett \& Arnold 1998). Van Alstyne (1988), for example, observed induction in phlorotannin production in Fucus distichus after simulated grazing. Yates \& Peckol (1993) and Peckol et al. (1996) found some evidence of induced phlorotannin production in F. vesiculosus due to simulated grazing and Arnold et al. (2001) found evidence of a role of methyl jasmonate in inducing phlorotannin production in F. vesiculosus. Pavia \& Toth (2000) showed that Ascophyllum nodosum responds to grazing by the gastropod Littorina obtusata by increasing its phlorotannin concentration and that increased phlorotannins provided resistance to further gastropod grazing. On the other hand, phlorotannins were not affected after grazing by the isopod Idotea granulosa or simulated herbivory, implying that the consequences of herbivory to induced responses are species-specific. Also, inducible responses to natural or simulated grazing have been found, e.g. in the non-fucacean brown algae Dictyota menstrualis (Cronin \& Hay 1996a) and several kelp species (Hammerström et al. 1998). However, generalizations about the prevalence of induced responses, and especially about their defensive role, are difficult to make since inducible responses to natural or simulated grazing in brown algae have not always been found (see e.g. Lowell et al. 1991, Pfister 1992, Steinberg 1994, Pavia et al. 1997, Toth \& Pavia 2000, 2002).

The variance in the occurrence of induced responses may be due to environmental variation. Resourcebased theories on the allocation of resources in plants (the carbon-nutrient balance hypothesis and the growth-differentiation balance hypothesis; Bryant et al. 1983, Herms \& Mattson 1992) predict that when external nutrient resources are abundant, primary allocation will be to growth at the expense of the production of carbon-based, quantitative chemical defenses. Conversely, when nutrient resources are scarce, growth will be suppressed and defense increased. The costs of allocating carbon to secondary metabolites are expected to increase with improving nutrient resources (Herms \& Mattson 1992). The inducible allocation of resources to defensive substances after herbivore grazing may thus be reduced in conditions where ambient nutrient concentrations are elevated. Eutrophication in coastal waters, for instance, may alter resource allocation patterns in the algae, affecting plant-herbivore interactions. Although the covariation of phlorotannin production with resource availability has been shown in several studies (Ilvessalo \& Tuomi 1989, Yates \& Peckol 1993, Arnold et al. 1995, Steinberg 1995, Pavia et al. 1999, Pavia \& Toth 2000), there is little information as to the effect of nutrient availability on the capability of algae to induce chemical responses to loss of tissue. Existing studies provide indirect evidence that resource availability may modify algal responses to herbivore grazing (Yates \& Peckol 1993, Peckol et al. 1996).

When grazing of one frond increases the probability of the other fronds being grazed too, the ability to spread the induction of defenses should be beneficial and favored by selection. Given this, it would pay for the alga to spread the induction among adjacent fronds and among different tissue types of different fitness value, e.g. between non-growing older tissues and growing apical meristems. Although algae have a poorly developed vascular system, they may contain a series of tracheal cells forming a primitive transport system within the algal thallus (Moss 1983, Diouris \& Floc'h 1984). To our knowledge, there are only 2 previous studies which have examined the spread of induction in brown algae. Van Alstyne (1988) concluded that Fucus vesiculosus is capable of increasing its phlorotannin concentration (i.e. resistance) after simulated grazing, but the evidence of the spread of induction remained uncertain. Toth \& Pavia (2000) studied inducible responses in Ascophyllum nodosum, and suggested that water-borne cues due to herbivory may induce resistance even in ungrazed nearby individuals. Locally induced resistance may benefit the plant by dispersing future damage over a larger area within the plant individual. The total biomass loss due to herbivory would then be equal but the pattern of damage different (Marquis 1992), reducing the probability of losing whole fronds due to disintegration of the thallus.

To minimize the costs of maintaining resistance, the duration of induction will presumably be adjusted to the prevailing risk of herbivore attack. In general, rapidly occurring and fading resistance will be most effective against relatively mobile herbivores (e.g. fishes 
or isopods), while long-lasting induction is likely to evolve in response to less mobile herbivores (e.g. gastropods) and when duration of the herbivory peak is prolonged (Karban \& Baldwin 1997).

The present study is the first to observe experimentally the effect of resource availability on the occurrence, spread and duration of inducible resistance in Fucus vesiculosus. The following 5 questions are explored: (1) Are different parts of the alga equally able to induce resistance? (2) How rapidly does induction occur and how long does it last? (3) Does the induction spread within the algal individual? (4) Does the loss of biomass affect the subsequent growth of $F$. vesiculosus? (5) Does nutrient enhancement modify the occurrence, spread or duration of induced resistance?

\section{MATERIALS AND METHODS}

Study organisms. Fucus vesiculosus L. (Phaeophyceae: Fucales) is widely distributed along the western and eastern sides of the Atlantic Ocean (Lüning 1990). In our study area, the Archipelago Sea, SW Finland, it is the only perennial brown rockweed of the littoral community, forming dense vegetation belts in shallow, hard-bottom habitats. Specimens for the experiments were collected from a single growing site close to the Archipelago Research Institute of the University of Turku (60 $\left.14^{\prime} \mathrm{N}, 2^{\circ} 40^{\prime} \mathrm{E}\right)$ in June 1999.

Idotea baltica (Pallas; Isopoda; Crustacea) is a common generalist herbivore occurring in the littoral zone of the brackish Baltic Sea. After the juvenile stage its diet consists mainly of Fucus vesiculosus (Salemaa 1987, Schaffelke et al. 1995, Jormalainen et al. 2001a) and, to a lesser extent, of filamentous epiphytic algae. The presence of $I$. baltica in F. vesiculosus habitats is highly variable over the course of the year. Juveniles are released in July, and the highest herbivore density and grazing pressure is reached in August. The number of individuals declines gradually towards winter and spring, after which the over-wintered individuals start to reproduce.

Manipulation of Fucus vesiculosus. Partial removal of the algal thallus, mimicking loss of biomass due to herbivore grazing, was carried out by artificial clipping, after which the alga was reared in either control or nutrient-enhanced conditions. Each clipped algal part was left with a sufficient amount of leafy tissue around the midrib. From each algal individual, 24 vegetative tips were collected and randomly assigned to each treatment combination. The treatments included 2 kinds of algal parts - clipping and nutrient manipulation. Half $(\mathrm{n}=12)$ of the tips were 'short tips' and half were 'long tips'. Half $(n=6)$ of both types of tips were clipped and the other half acted as a non-clipped con- trol. The tips were then assigned to either ambient $(n=3)$ or enriched nutrient $(n=3)$ conditions. One of the 3 tips in each of these groups was used in herbivore preference tests 2, 10 and $38 \mathrm{~d}$ after clipping the parts used and the initial clipping patterns are shown in Fig. 1a. Part A was a small part with 2 unclipped apical fronds; Part B was similar to Part A, with 2 apical fronds but 1 of these was clipped from the sides of the thallus leaving meristematic tissue and midrib unclipped to allow further growth; Part $\mathrm{C}$ was a large part containing older unclipped thallus; and Part D was similar to Part C, but was clipped from the basal thallus around the midrib. Shortly after clipping, the algal parts were photographed, fastened to a clothes-pin (with all apical tips adjusted to the same depth of $15 \mathrm{~cm}$ to ensure equal light conditions for all the algae), and randomly assigned to either nutrient-enhanced or control pools. The $60 \mathrm{l}$ flow-through pools $(\mathrm{n}=16)$ were situated outdoors in natural light conditions. The water was changed continuously at a rate of $180 \mathrm{ld}^{-1}$.

Half the pools received $30 \mathrm{mg}$ NPK fertilizer (Kemira Agro; N:P:K ratio 20:2:8) 3 times a day through automatic feeders to raise the ambient nutrient concentration. The ambient nutrient levels during the manipulation period were monitored with water samples taken randomly in relation to the timing of nutrient addition. Nutrients were analyzed by the standardized methods used by the Finnish National Board of Waters (Koroleff 1976). The nutrient concentrations $\left(\mu \mathrm{g} \mathrm{l}^{-1}\right.$; mean $\pm \mathrm{SD}$, [n]) were as follows - total nitrogen: $225 \pm 120$ (2),

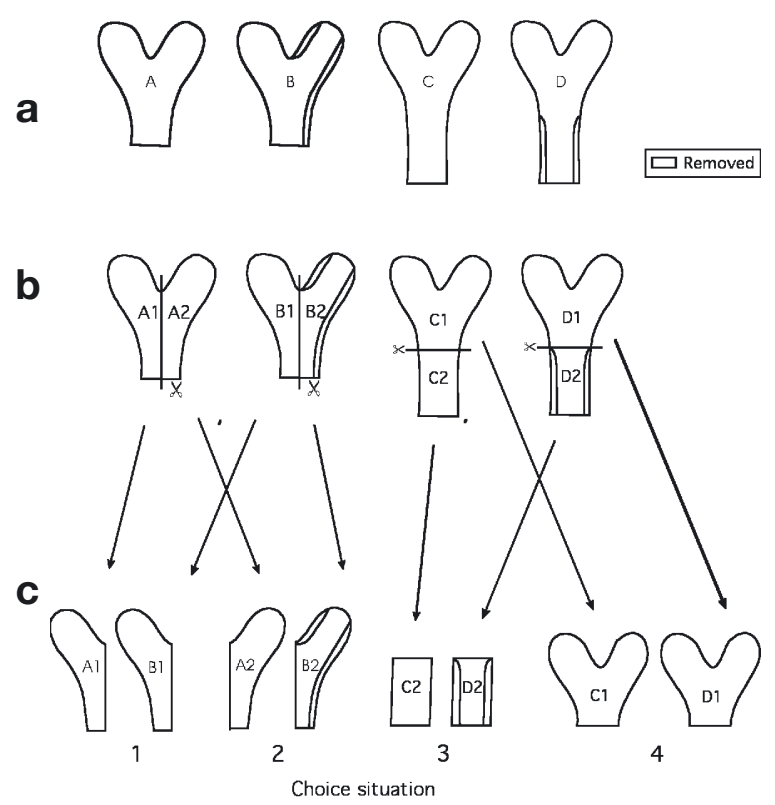

Fig. 1. Fucus vesiculosus. (a) Parts used in simulated grazing experiment; (b) division patterns of algal parts after manipulation periods of 2,10 and $38 \mathrm{~d}$, prior to feeding preference bioassays; (c) 4 different choice situations for feeding preference bioassays. Removed: parts clipped off fronds 
$404 \pm 182$ (8); ammonia: $\mathrm{NH}_{4} 1.0 \pm 0$ (2), $5.3 \pm 3.4$ (8); phosphate: $\mathrm{PO}_{4} 8.0 \pm 2.8$ (2), $21.1 \pm 17.8(8)$, in the control and nutrient-enhanced pools, respectively. The nutrient levels in the nutrient-addition treatment corresponded closely to the ambient levels observed along the eutrophicated littoral coasts of the study area.

Herbivore preference tests. After cultivation periods of 2, 10 and $38 \mathrm{~d}$ following simulated grazing, the algal parts were each cut in half (cutting patterns shown in Fig. 1b) for the feeding-preference bioassays. The bioassays were conducted under laboratory conditions to assess the preference of Idotea baltica for clipped or control algae reared in control and nutrient-enhanced environments. Because of sexual differences in the magnitude of feeding preferences (Jormalainen et al. $2001 \mathrm{a}, \mathrm{b})$, we used only male I. baltica in the feeding preference experiments. The isopods for the bioassays were collected from the same site as the alga.

The preference bioassays were conducted in 11 glass containers, with one Idotea baltica individual able to choose between 2 algal pieces: 1 clipped or adjacent to a clipped specimen, the other unclipped as a control. Each trial lasted $5 \mathrm{~d}$. We used 4 different pairs of algal pieces (hereafter 'choice situations') to investigate the occurrence and spreading of induced resistance within the alga. The different choice situations are shown in Fig. 1c. Thus inducible resistance was assumed to have occurred if Parts B2 and D2, in Choice Situations 2 and 3 , respectively, were consumed less than Parts A2 and C2. Similarly, a spread of induction to the neighboring frond or from the basal thallus to the apices was assumed if Parts B1 and D1, in Choice Situations 1 and 4, respectively, were consumed less than Parts A1 and C1. In Choice Situations 1 and 4, in which the 2 algal pieces were otherwise indistinguishable, one randomly chosen piece was marked with a thin sewing thread. The algal pieces were digitally photographed at the beginning and end of the $5 \mathrm{~d}$ feeding trials, and the surface area consumed by the herbivore was calculated as the absolute area consumed (rather than for instance the final area of the pieces minus the initial area). An example of a pair of digital photographs of the algae at the beginning and end of the feeding preference bioassays is shown in Fig. 2.

In the feeding preference experiments, the algae reared in the nutrient-addition treatment received water slightly enriched with inorganic nutrients $\left(20 \mu \mathrm{g} \mathrm{l}^{-1}\right.$ nitrate $\mathrm{NO}_{3}-\mathrm{N}, 60 \mathrm{\mu g} \mathrm{l}^{-1}$ ammonia $\mathrm{NH}_{4}-\mathrm{N}$ and $15 \mu \mathrm{g} \mathrm{l} \mathrm{l}^{-1}$ phosphate $\mathrm{PO}_{4}-\mathrm{P}$ ) to prevent the algal quality from changing during the $5 \mathrm{~d}$ assay. Nutrient-enriched water does not directly affect $I$. balthica, as shown in Hemmi \& Jormalainen (2002).

The test containers were kept at 12 to $13^{\circ} \mathrm{C}$, under a 17:7 h light:dark regime and aeration.
Illumination was provided by four $400 \mathrm{~W}$ sodium vapor lamps (Sylvania) to enable algal photosynthesis during the feeding preference trials.

Chemical analyses and measurements of algal growth. The total content of phenolics (referred to in the following as phlorotannins [Ragan \& Glombitza 1986]) in the algae was measured by a modification of the Folin-Ciocalteau technique (Nurmi et al. 1996). Phloroglucinol was used as a standard agent. For practical reasons, the phlorotannin determination was carried out on algal parts different than those used in the bioassays. The chemical analyses were run on freezedried and finely ground algal material stored at $-20^{\circ} \mathrm{C}$ until determination.

To control the initial concentration of phlorotannins in all parts used in the bioassays, we measured the phlorotannin concentration immediately (within a few minutes) after simulated grazing by the algae, when no induction was assumed to have yet occurred. No initial differences were found between the 7 different parts of the algae (A1+A2 combined, B1, B2, C1, C2, D1, D2 in Fig. $1 \mathrm{~b}$; phlorotannin concentration: $9.38 \pm 0.1 \%$ of dry matter, mean $\left.\pm 1 \mathrm{SE}, \mathrm{n}=43 ; F_{6,36}=0.71, \mathrm{p}=0.65\right)$. Hence any subsequent differences between the parts must have been due to possible induction arising from simulated grazing and from the subsequent rearing conditions.

Algal growth was determined as the wet weight increment (final wet weight-initial wet weight) during the manipulation period of $38 \mathrm{~d}$. Prior to weighing the algae, the epiphytes were removed and excess water dried off between paper tissues.

Statistical analyses. Induced resistance, in terms of feeding preferences after simulated grazing, was analyzed by repeated-measures ANOVA (unstructured covariance matrix based on Akaike's information criteria), with consumption of the clipped piece or its neighbor versus the control piece in the same container as the repeated measure. Since time from the simulated grazing affected the preferences, we ran separate analyses for the bioassays conducted 2, 10 and $38 \mathrm{~d}$ after simulated grazing. Also, we conducted

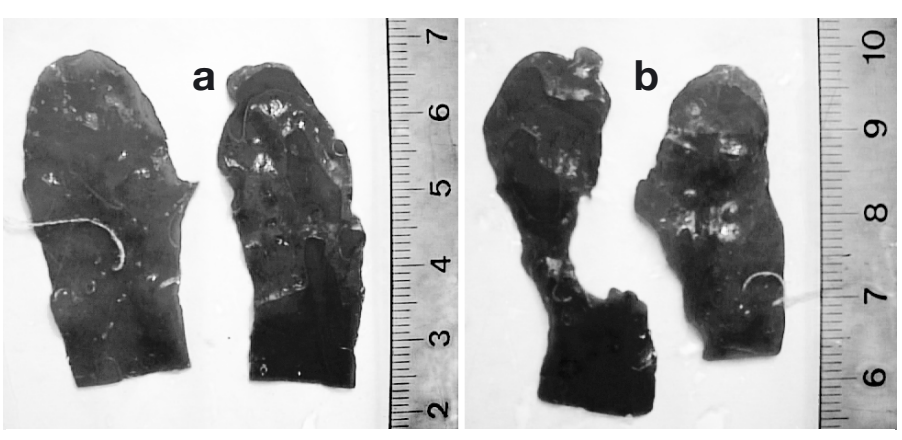

Fig. 2. Fucus vesiculosus. Digital photographs of the alga at (a) the beginning and (b) the end of the feeding preference bioassays 
separate analyses to test the occurrence of induction in the clipped pieces (including Choice Situations 2 and 3 in Fig. 1c) and to test the spreading of induction within the alga (including Choice Situations 1 and 4 in Fig. 1c). Within each analysis, nutrient treatment and choice situation were used as grouping factors; thus their interaction with the repeated factor (preference) would indicate variation in induced resistance as a function of nutrient environment, or dissimilar occurrence in clipped and neighboring fronds. Interactions between nutrient treatment $\times$ choice situation $\times$ preference were not significant $(p>0.10)$ in any of the tests, nor did they influence the significance of the other factors; thus they could be excluded from the statistical models.

Differences in phlorotannin concentrations between parts of the alga and nutrient treatments were analyzed by 3-way ANOVA using simulated grazing, nutrient treatment and time as grouping factors. We conducted separate analyses for short and long tips. The factor 'time' and its interactions appeared to be significant in the analyses conducted with pooled data consisting of either the small or the large parts of the algae. We therefore ran separate 2-way ANOVAs again for the different time intervals.

Growth of Fucus vesiculosus was analyzed by 2-way ANCOVA, with data adjusted for the initial size of the algal part.

To ensure that the assumptions for ANOVA were fulfilled, Levene's test was used to test for homogeneity of variances and the Kolmogorov-Smirnov test to test for normality of the residual variation. All statistical analyses were performed using linear mixed models or general linear models (procedures MIXED and GLM in SAS 8.01 statistical software; SAS Institute 2000).

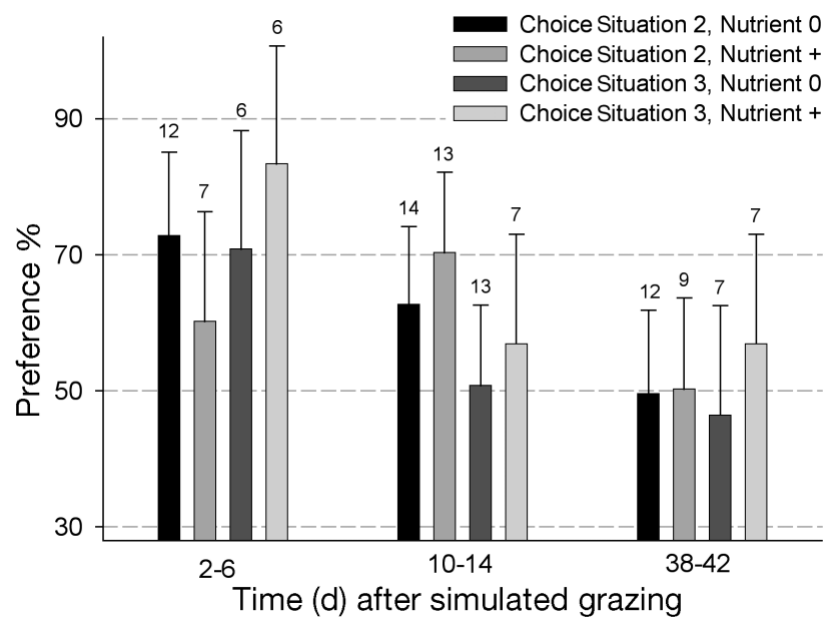

\section{RESULTS}

\section{Herbivore preference}

In the experiment conducted with the clipped parts (A2 vs B2, C2 vs D2 in Fig. 1c) $2 \mathrm{~d}$ after simulated grazing, the herbivores clearly preferred the parts without clipping: mean $\pm \mathrm{SE}(\mathrm{n})$ consumption $\left(\mathrm{cm}^{2}\right)=0.20 \pm$ 0.04 (49) and $0.07 \pm 0.02$ (46) for control and clipped parts, respectively) (Table 1, Fig. 3a). Nutrient treatment did not affect the average consumption rate, but the apical parts in Choice Situation 2 were consumed significantly more than the basal parts in Choice Situation 3: $0.18 \pm 0.03(48)$ and $0.09 \pm 0.03(47)$, respectively (Table 1). There were no significant interactions between preference and either nutrient treatment or choice situation, indicating that induced resistance occurred in both nutrient environments and in both apical and basal parts (Table 1).

Induced resistance was still effective in the clipped parts $10 \mathrm{~d}$ after simulated grazing $-0.35 \pm 0.06$ (53) and $0.18 \pm 0.03$ (55) for control and clipped parts, respectively - and apical parts were again consumed more than basal parts $-0.37 \pm 0.04$ (54) and $0.16 \pm 0.04$ (54), respectively - (Table 1, Fig. 3a). In addition, there was a significant nutrient $x$ choice situation interaction in the total consumption of the algal parts. In the control algae, apical (Choice Situation 2) and basal (Choice Situation 3) parts were consumed in equal amounts$\mathrm{cm}^{2}$, adjusted mean $\pm \mathrm{SE}(\mathrm{n})=0.30 \pm 0.05(28)$ and $0.21 \pm 0.05(27)$, respectively-while in the nutrienttreated algae the average consumption of apical parts was considerably higher than that of basal ones$0.43 \pm 0.05(26), 0.12 \pm 0.05(27)$, respectively-(Table 1 ).

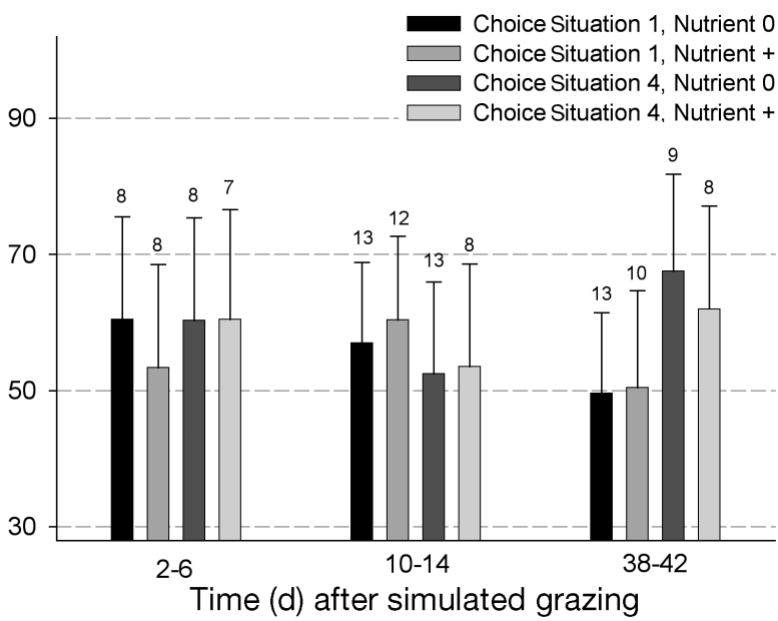

Fig. 3. Idotea baltica grazing on Fucus vesiculosus. Relative preference during 5 d bioassay (mean + SE; $\mathrm{n}$ above bars) showing control alga consumed as proportion of total consumption (consumption of control alga/[consumption of clipped + control algae] $\times 100$ ) in each treatment combination. (a) Choice Situations 2 and 3 (control vs simulated grazing), (b) Choice Situations 1 and 4 (control vs fronds adjacent to parts subjected to simulated grazing). Value of $100 \%$ indicates complete preference for control pieces, i.e. highest possible inducible resistance, while value of $50 \%$ indicates complete absence of preference 
Table 1. Idotea baltica grazing on Fucus vesiculosus. Statistical results of repeated-measures ANOVA testing herbivore food preferences between control and clipped alga and effects of nutrient enhancement and choice situation on average consumption and preferences. Choice situations were the choice between apical parts (Choice Situation 2) and basal parts (Choice Situation 3) (see Fig. 1c). Preference data are shown in Fig. 3a. Statistically significant results are in bold

\begin{tabular}{|lrrc|}
\hline Source & df & $F$ & $\mathrm{p}$ \\
\hline $\mathbf{2 ~ d}$ & & & \\
Preference & 1,49 & 7.62 & $\mathbf{0 . 0 0 8}$ \\
Nutrient & 1,49 & 2.35 & 0.132 \\
Choice Situation & 1,49 & 5.12 & $\mathbf{0 . 0 2 8}$ \\
Preference $\times$ Nutrient & 1,49 & 0.07 & 0.790 \\
Preference $\times$ Choice Situation & 1,49 & 0.35 & 0.559 \\
Nutrient $\times$ Choice Situation & 1,49 & 2.14 & 0.150 \\
$\mathbf{1 0}$ d & & & \\
Preference & 1,52 & 5.38 & $\mathbf{0 . 0 2 4}$ \\
Nutrient & 1,52 & 0.23 & 0.634 \\
Choice Situation & 1,52 & 14.02 & \\
$<\mathbf{0 . 0 0 1}$ & & & \\
Preference $\times$ Nutrient & 1,52 & 0.86 & 0.359 \\
Preference $\times$ Choice Situation & 1,52 & 3.47 & 0.068 \\
Nutrient $\times$ Choice Situation & 1,52 & 5.64 & $\mathbf{0 . 0 2 1}$ \\
38 d & & & \\
Preference & 1,55 & 0.57 & 0.454 \\
Nutrient & 1,55 & 0.46 & 0.499 \\
Choice Situation & 1,55 & 0.80 & 0.376 \\
Preference $\times$ Nutrient & 1,55 & 0.25 & 0.618 \\
Preference $\times$ Choice Situation & 1,55 & 0.08 & 0.773 \\
Nutrient $\times$ Choice Situation & 1,55 & 0.44 & 0.511 \\
\hline
\end{tabular}

Later, 38 d after simulated grazing, there was no induced resistance or any other treatment effects or their interactions with preference (Table 1, Fig. 3a).

In the feeding preference experiment conducted between the control and parts neighboring those subjected to simulated grazing (A1 vs B1, C1 vs D1 in Fig. 1c), 2 d after simulated grazing Idotea baltica tended to prefer control pieces over parts neighboring clipped parts; the difference, however, was not significant-0.21 \pm 0.04 (52) and $0.11 \pm 0.03$ (49), respectively-(Table 2, Fig. 3b), suggesting that induced resistance may not spread to neighboring fronds. The preference was similar in both choice situations, as revealed by non-significant preference $\times$ choice situation interaction; this suggests an absence of spread of induction to both neighboring fronds and to the apices above the simulated grazing.

After $10 \mathrm{~d}$ there was no indication of induced resistance. This implies that the weak spreading of induced resistance to nearby fronds possibly occurring $2 \mathrm{~d}$ after simulated grazing had faded away
Table 2. Idotea baltica grazing on Fucus vesiculosus. Statistical results of repeated-measures ANOVA testing herbivore food preferences between control algal parts and parts adjacent to clipped parts and effects of nutrient enhancement and choice situation on average consumption and preferences. Choice situations were choice between neighboring frond (Choice Situation 1) or between apical part above clipped part (Choice Situation 4) and control part (see Fig. 1c). Preference data are shown in Fig. 3b

\begin{tabular}{|lccc|}
\hline Source & df & $F$ & $p$ \\
\hline $\mathbf{2 ~ d}$ & & & \\
Preference & 1,48 & 3.53 & 0.066 \\
Nutrient & 1,48 & 0.02 & 0.881 \\
Choice Situation & 1,48 & 0.90 & 0.349 \\
Preference $\times$ Nutrient & 1,48 & 0.27 & 0.603 \\
Preference $\times$ Choice Situation & 1,48 & 0.08 & 0.779 \\
Nutrient $\times$ Choice Situation & 1,48 & 0.37 & 0.548 \\
$\mathbf{1 0}$ d & & & \\
Preference & 1,52 & 2.18 & 0.146 \\
Nutrient & 1,52 & 1.39 & 0.244 \\
Choice Situation & 1,52 & 5.18 & $\mathbf{0 . 0 2 7}$ \\
Preference $\times$ Nutrient & 1,52 & 0.48 & 0.494 \\
Preference $\times$ Choice Situation & 1,52 & 0.01 & 0.932 \\
Nutrient $\times$ Choice Situation & 1,52 & 2.07 & 0.157 \\
$\mathbf{3 8 ~ d}$ & & & \\
Preference & 1,54 & 1.06 & 0.309 \\
Nutrient & 1,54 & 0.42 & 0.520 \\
Choice Situation & 1,54 & 1.77 & 0.189 \\
Preference $\times$ Nutrient & 1,54 & 0.42 & 0.521 \\
Preference $\times$ Choice Situation & 1,54 & 0.51 & 0.479 \\
Nutrient $\times$ Choice Situation & 1,54 & 0.08 & 0.772 \\
\hline
\end{tabular}

between Days 3 and 10 (Table 2, Fig. 3b). The average food consumption of the herbivores differed between the 2 choice situations: the algal parts in Choice Situation 4 were consumed more than in Choice Situation $1-0.33 \pm 0.03(48)$ and $0.23 \pm 0.03$ (55), respectively-

Table 3. Fucus vesiculosus. Results of 3-way ANOVA testing effects of simulated grazing (clipping), nutrient enhancement and time on phlorotannin concentration. Clipping refers to differences between (a) small (A, B1 and B2) or (b) large (C1, C2, D1, D2) parts of alga. Data are shown in Figs. 4 \& 5

\begin{tabular}{|lcccrc|}
\hline \multicolumn{1}{l}{ Source } & df & Type III SS & MS & $F$ & p \\
\hline (a) Small algal parts A, B1, B2 & & & & & \\
Clipping & 2,84 & 0.178 & 0.089 & 0.25 & 0.777 \\
Nutrient & 1,84 & 20.48 & 20.48 & 58.33 & $<\mathbf{0 . 0 0 0 1}$ \\
Time & 2,84 & 33.45 & 16.73 & 47.65 & $<\mathbf{0 . 0 0 0 1}$ \\
Clipping $\times$ Nutrient & 2,84 & 0.019 & 0.010 & 0.03 & 0.973 \\
Clipping $\times$ Time & 4,84 & 0.770 & 0.193 & 0.55 & 0.701 \\
Nutrient $\times$ Time & 2,84 & 22.75 & 11.38 & 32.41 & $<\mathbf{0 . 0 0 0 1}$ \\
Clipping $\times$ Nutrient $\times$ Time & 4,84 & 1.817 & 0.454 & 1.29 & 0.279 \\
(b) Large algal parts C1, C2, D1, D2 & & & & \\
Clipping & 3,91 & 1.478 & 0.493 & 1.14 & 0.337 \\
Nutrient & 1,91 & 11.71 & 11.71 & 27.10 & $<\mathbf{0 . 0 0 0 1}$ \\
Time & 2,91 & 16.43 & 8.216 & 19.02 & $<\mathbf{0 . 0 0 0 1}$ \\
Clipping $\times$ Nutrient & 3,91 & 0.736 & 0.245 & 0.57 & 0.638 \\
Clipping $\times$ Time & 6,91 & 10.95 & 1.825 & 4.22 & $<\mathbf{0 . 0 0 1}$ \\
Nutrient $\times$ Time & 2,91 & 9.686 & 4.843 & 11.21 & $<\mathbf{0 . 0 0 0 1}$ \\
Clipping $\times$ Nutrient $\times$ Time & 6,91 & 4.328 & 0.721 & 1.67 & 0.137 \\
\hline
\end{tabular}


(Table 2). This may follow from the larger total number of apices consumed in Choice Situation 4.

In the test $38 \mathrm{~d}$ after simulated grazing, we found no significant preference, nutrient effect or difference in choice situations, or any interactions among them; nutrient enhancement did not affect induced resistance in any of the bioassays (Tables 1 \& 2).

\section{Chemical quality and growth of Fucus vesiculosus}

Simulated grazing of small parts of the alga (Parts A, B1, B2) did not affect its phlorotannin concentrations (Table 3a, Fig. 4). Nutrient treatment had a major effect on phlorotannins, the size of the effect depended on time after simulated grazing (Table 3a, Fig. 4), leading us to analyze clipping and nutrient effects separately for each time interval. Nutrient treatment significantly decreased the phlorotannin concentrations of the alga, the magnitude of the effect increasing with increasing duration of nutrient treatment and being statistically significant after $38 \mathrm{~d}$ (Table 4a, Fig. 4).

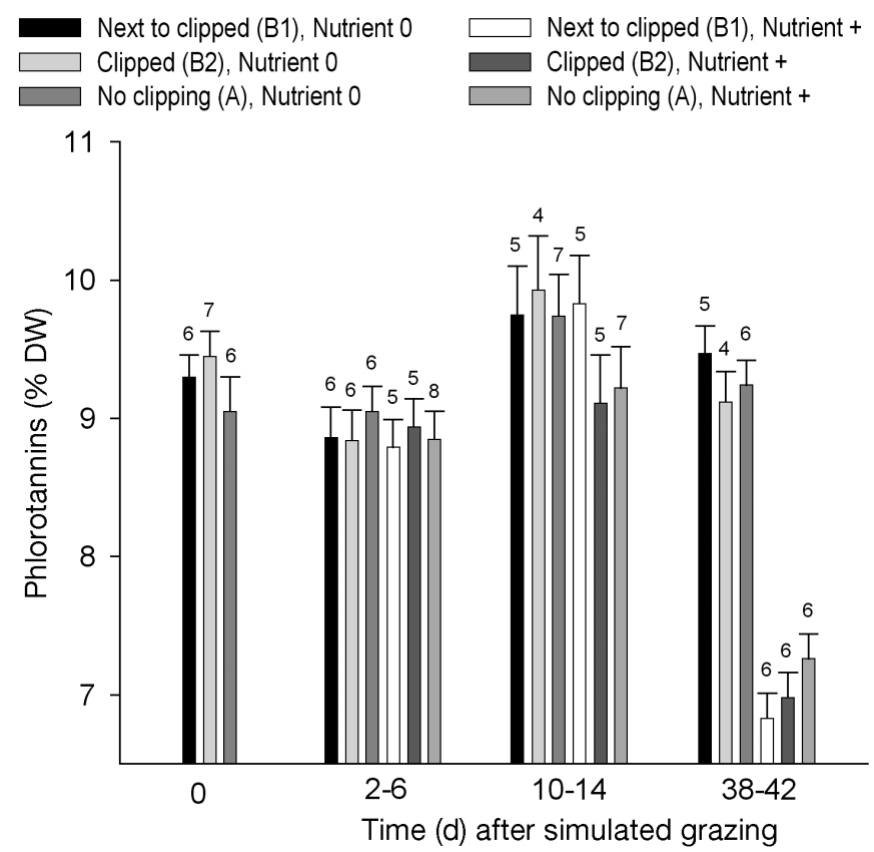

Fig. 4. Fucus vesiculosus. Phlorotannin concentration (adjusted mean $+\mathrm{SE}_{\text {; }} \mathrm{n}$ above bars) of clipped fronds, of fronds adjacent to clipped fronds and of control fronds of small parts $A$ and $B$ before (Time 0 ) and 2, 10 and $38 \mathrm{~d}$ after simulated grazing. DW: dry weight
For the large algal parts, the effects of nutrient treatment and time after simulated grazing were interdependent, and the effect of clipping depended on time (Tables $3 b \& 4 b$ ). Since we had data for both the basal and the apical parts, with the basal part undergoing simulated grazing and the apical part reflecting the possible transfer of induction, we tested the differences between control and clipped algae, contrasting apical pieces with each other and basal pieces with each other: $2 \mathrm{~d}$ after simulated grazing, the phlorotannin level was significantly higher in the clipped parts (Table 4b, Fig. 5). The difference between clipped and control algae was marginally significant in the apical parts (a priori contrasts: $F_{1,40}=3.97, \mathrm{p}=0.053$ ) (Fig. 5a), and especially clear in the basal parts (a priori contrasts: $F_{1,40}=6.25, \mathrm{p}=0.017$ ) (Fig. 5b). The initial phlorotannin levels, however, were generally higher compared to the situation $2 \mathrm{~d}$ after beginning the manipulation (Fig. 5). Nutrient enhancement did not have an effect on phlorotannin concentration $2 \mathrm{~d}$ after simulated grazing (Table 4b, Fig. 5).

Phlorotannins did not differ between the parts $10 \mathrm{~d}$ after clipping, but nutrient enhancement had started to reduce the phlorotannin concentration (Table $4 \mathrm{~b}$, Fig. 5).

Long-term (38 d) nutrient enhancement resulted in an overall decrease in phlorotannins (Table 4, Fig. 5). Clipping significantly affected phlorotannin concentration, but in the opposite direction than $2 \mathrm{~d}$ after simulated grazing: the clipped parts contained fewer phlorotannins than the control parts. These differences were greatest among the nutrient-treated algae, as indicated by the trend in the clipping $\times$ nutrient enhancement interaction (Table 4b). A priori contrasts were therefore calculated separately for the control and nutrient treatments: in control water the differ- 

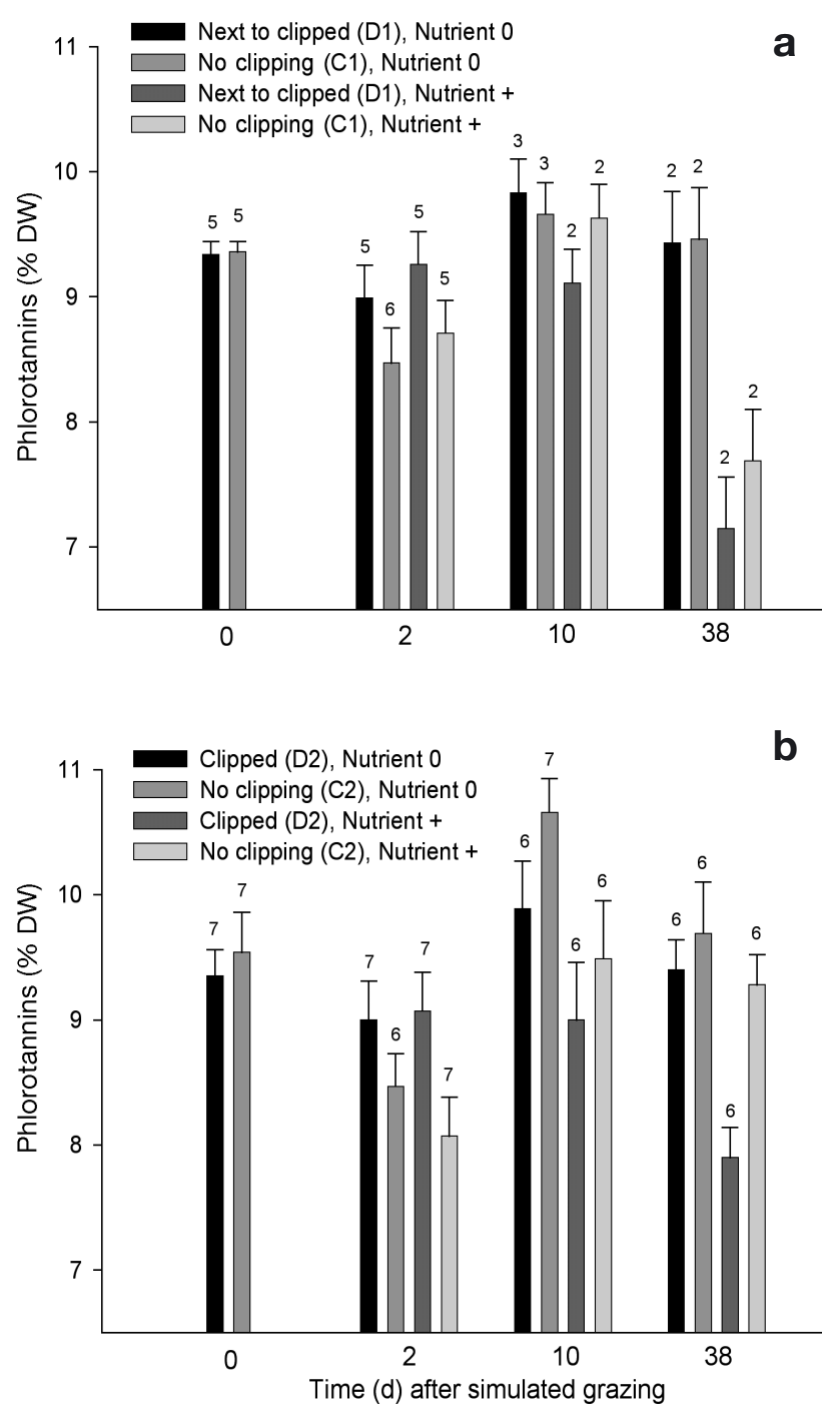

Fig. 5. Fucus vesiculosus. Phlorotannin concentration (adjusted mean $+\mathrm{SE}_{\text {; }} \mathrm{n}$ above bars) of (a) apical and (b) basal thallus of clipped and control large parts $C$ and D before (Time 0) and 2, 10 and $38 \mathrm{~d}$ after simulated grazing ences were non-significant for both basal and apical parts $\left(F_{1,12}=0.30, \mathrm{p}=0.595\right.$ and $F_{1,12}=0.01, \mathrm{p}=0.915$, respectively), while in nutrient-enriched water they were marginally significant in basal parts $\left(F_{1,12}=4.78\right.$, $\mathrm{p}=0.049)$ and non-significant in apical parts $\left(F_{1,12}=\right.$ 2.19, $\mathrm{p}=0.164)$.

Simulated grazing had no effect on the subsequent growth of the algae; the increase in wet weight did not differ between clipped and control parts (Table 5). Algae grown in a nutrient-enhanced environment grew less than those grown in ambient nutrient conditions. This was the case for both small and large pieces of Fucus vesiculosus (Table 5).

In a comparison of the group means of different parts at 2 nutrient levels, algal growth tended to correlate positively with phlorotannin concentration ( $\mathrm{r}=0.657$, $\mathrm{p}=0.077, \mathrm{n}=8$; Fig. 6).

The food consumption of the herbivores did not correlate significantly with phlorotannin concentration of the algal parts in any treatment or at any point of time: pooled data; values calculated as control part minus clipped part or part neighboring the clipped part (Fig. 1b), 2 nutrient treatments and 3 times: $\mathrm{r}=$ $0.089, \mathrm{p}=0.678, \mathrm{n}=24$.

\section{DISCUSSION}

Simulated grazing by clipping of the thallus did induce resistance in clipped parts in Fucus vesiculosus, independent of nutrient environment. In the feeding preference bioassays shortly after simulated grazing, Idotea baltica preferred the unclipped control alga to the clipped alga. This implies that inducible resistance of $F$. vesiculosus occurs quite rapidly after wounding and starts to diminish after $10 \mathrm{~d}$. The observed resistance, however, was not related to total phlorotannin concentrations; clipping did not induce changes in

Table 5. Fucus vesiculosus. Growth (g wet weight increments: mean \pm SE) of small and large parts of alga $38 \mathrm{~d}$ after simulated grazing, and results of ANCOVA. Initial wet weight of alga was used as covariate

\begin{tabular}{|c|c|c|c|c|c|c|}
\hline Treatment & Nutrient 0 & Nutrient + & Source & $\mathrm{df}$ & $F$ & $\mathrm{p}$ \\
\hline \multicolumn{7}{|l|}{ Small parts } \\
\hline Control & $0.42 \pm 0.03(20)$ & $0.32 \pm 0.03(20)$ & Clipping & 1,115 & 0.02 & 0.885 \\
\hline \multirow[t]{3}{*}{ Clipped } & $0.43 \pm 0.02(40)$ & $0.30 \pm 0.02(40)$ & Nutrient & 1,115 & 21.14 & $<0.0001$ \\
\hline & & & Clipping $\times$ Nutrient & 1,115 & 0.27 & 0.602 \\
\hline & & & Initial weight & 1,115 & 85.06 & $<0.0001$ \\
\hline \multicolumn{7}{|l|}{ Small parts } \\
\hline Control & $0.60 \pm 0.04(20)$ & $0.57 \pm 0.04(20)$ & Clipping & 1,73 & 0.68 & 0.413 \\
\hline \multirow[t]{3}{*}{ Clipped } & $0.69 \pm 0.04(20)$ & $0.55 \pm 0.04(18)$ & Nutrient & 1,73 & 4.54 & 0.036 \\
\hline & & & Clipping $\times$ Nutrient & 1,73 & 1.74 & 0.192 \\
\hline & & & Initial weight & 1,73 & 42.05 & $<0.0001$ \\
\hline
\end{tabular}




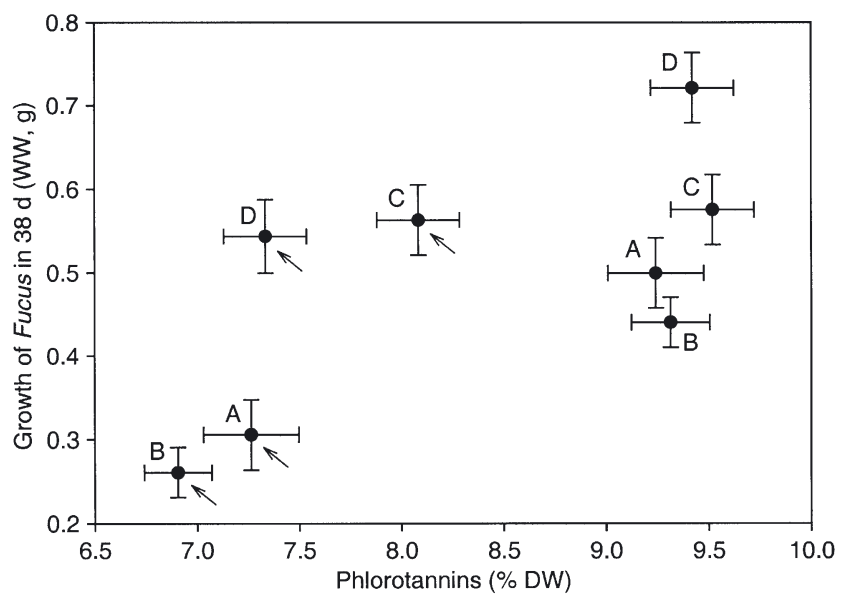

Fig. 6. Fucus vesiculosus. Correlation between growth and phlorotannin concentration of 4 different treatments (mean \pm SE). Data points indicated by arrow represent alga grown in nutrient-enriched water. DW: dry $\mathrm{wt}_{\text {; }} \mathrm{WW}$ : wet wt. A-D: clipping treatments shown in Fig. 1a

these, and the phlorotannin concentration in F. vesiculosus did not predict the preference of $I$. baltica. Phlorotannin concentration was highly dependent on the nutrient environment: the concentration decreased with time in nutrient-enhanced conditions, and this decrease was independent of simulated grazing.

The isopod's preference for control alga over clipped alga together with no induction of changes in total phlorotannin content strongly suggests that there are substances other than phlorotannins involved in the induction of grazing deterrence in Fucus vesiculosus. Deal et al. (2003) quantified metabolites responsible for grazing deterrence of sea urchins in $F$. vesiculosus, and concluded that galactolipids and some nonphenolic water-soluble compounds rather than phlorotannins produced the strongest deterrence. Alternatively, qualitative changes in different fractions of phlorotannins may explain the herbivore preference and consumption rate of $F$. vesiculosus, since the deterrence capacity of phlorotannins may vary according to their molecular structure (Boettcher \& Targett 1993, Arnold \& Targett 1998, Targett \& Arnold 1998). The chemical basis underlying the early induction of deterrence in $F$. vesiculosus against the isopod herbivore Idotea baltica remains unclear and requires further research.

The ecological and life-history traits of Fucus vesiculosus and Idotea baltica provide favorable preconditions for the evolution of inducible defenses. In our study area, I. baltica is the major herbivore of $F$. vesiculosus and, by feeding on the thallus, the only species capable of causing considerable biomass losses (Kangas et al. 1982 and pers. obs. of present authors). $F$. vesiculosus is a perennial, long-lived species, which encounters several peaks of herbivory by isopods during its lifespan (Salemaa 1979, 1987). The peak period in herbivory occurs during the few months in fall when the generation of isopods born in the summer begin feeding on Fucus, and isopod density may reach dozens to hundreds of isopods per individual $F$. vesiculosus; the values are 10-fold those in late spring and summer (Jormalainen et al. 1995 and unpubl. data of present authors). Moreover, I. baltica is highly mobile within and between algal individuals, and its presence is thus variable among the algae.

Since resistance induction was local and did not spread to neighboring fronds, it may not be a very efficient defense against biomass loss to highly mobile herbivores. On the other hand, a rapid local deterrence may be capable of dispersing grazing away from already grazed spots of thallus, thereby reducing the size of single grazing marks and also reducing the risk of the thallus being completely removed, which would greatly increase the magnitude of biomass loss due to grazing. Furthermore, the relatively rapid relaxation of the local induction would hardly provide an efficient defense against herbivory during a herbivory peak lasting for months. We therefore suggest that although the observed resistance may clearly provide adaptive benefits in defense against herbivory, the possibility remains that resistance arises as a side-effect of metabolic processes which have evolved in another context, for instance wound-healing of the damaged tissue.

Contrary to our expectations, based on earlier studies on brown algae (Van Alstyne 1988, Pavia \& Toth 2000), the total phlorotannin concentration clearly did not play any crucial role in the induced response. Simulated grazing increased the phlorotannin concentration only in the clipped basal parts after $2 \mathrm{~d}$, regardless of nutrient addition. Since phlorotannins are involved in the hardening of cell walls (Faberberg \& Dawes 1976, Schoenwaelder 2002), the rapid increase may be due to the possible wound-healing role of phlorotannins in the clipped, non-growing tissues. In addition, there was an overall decrease in phlorotannins after 2 $\mathrm{d}$ and an increase after $10 \mathrm{~d}$ in almost every treatment combination. We suspect this to be a consequence of natural changes in growing conditions (e.g. light and/or temperature) occurring in the outdoor pools at that time. Such responses can be expected if the levels of soluble phlorotannins vary with the growth rate of the alga (Arnold \& Targett 2003).

Nutrient enhancement reduced the concentration of phlorotannins, consistent with the prediction of the carbon-nutrient balance (CNB) hypothesis. However, as nutrient enhancement did not affect production of phlorotannins after simulated grazing, the CNB hypothesis was unable to predict correctly the consequences of nutrient enhancement on the occurrence 
of induced phlorotannin production by the alga. Nutrient enhancement likewise had no effect on feeding preferences, suggesting that the nutrient environment does not affect the induced response in any way. However, nutrient enhancement increased the consumption rate of apical pieces compared to that of basal pieces, suggesting possible changes in the primary metabolism of the growing tips that make them more susceptible to herbivory. This is consistent with the results by Hemmi \& Jormalainen (2002), who showed that Idotea baltica consumes more food and achieves a higher growth rate when reared on nutrient-treated Fucus vesiculosus.

The decrease in phlorotannins in the nutrientenhanced environment was not due to increased growth of the alga. Instead, we found a positive though weak correlation between growth rate and phlorotannin concentration, which contradicts the predictions of the CNB and GDB (growth-differentiation balance) hypotheses. Previous studies on brown algae have reported a variety of mixed results on the phlorotannin-growth relationship, suggesting a complex system with several factors influencing growth and secondary chemistry. The findings have been inconclusive: some authors have found a positive correlation between the growth and defense of Fucus vesiculosus (Cronin \& Hay 1996b under laboratory conditions), some have observed a negative correlation (Yates \& Peckol 1993 at high but not low N concentrations, Pavia et al. 1999), others have found a negative correlation in the brown alga Ecklonia radiata in spring but not in autumn (Steinberg 1995), and others have failed to track any resource-based tradeoffs (Cronin \& Hay 1996b under field conditions, Pavia \& Åberg 1996, Targett 2001). Rather than a straightforward trade-off between growth and phlorotannin concentration, the non-existing or positive phenotypic correlation in our case may thus have been due to the nutrient-addition treatment, which often increases the amount of epiphytic algae and other microorganisms on the surface of the thallus (authors' pers. obs.). Shading by epiphytes reduces the availability of light, causing carbon limitation; this may explain the lower levels of phlorotannins as well as the growth of $F$. vesiculosus in the nutrientaddition treatment.

If losing biomass to herbivory generates costs for the alga, then the induction of resistance may be regarded as a defensive strategy against further herbivory. A negative relationship between growth and artificial grazing has previously been found in the kelp Laminaria hyperborea (Toth \& Pavia 2002). However, clipping did not affect growth of Fucus vesiculosus. This indicates that the consequences of biomass loss may depend on growing conditions and do not necessarily affect the fitness of the alga. F. vesiculosus may be able to compensate for the loss of biomass by utilizing stored resources in the remaining thallus to maintain growth (Lehvo et al. 2001, Honkanen \& Jormalainen 2002). Another possibility is that under good conditions with high nutrient and light availability, F. vesiculosus does not need to rely on internal storages, but may sustain growth by resorting to external resources available in excess. Transfer of resources within the alga is probably most important under conditions in which external resources are scarce; in such a situation, thallus loss should affect growth. The availability of resources may have been relatively high in this study, and prevented artificial grazing from negatively affecting growth. The absence of this trade-off may partly be explained by the location of the artificial grazing marks: we intentionally avoided clipping the apical parts of the thallus, containing meristematic tissue, to avoid exaggeration of the magnitude of simulated grazing. The loss of meristematic tissue to herbivores would necessarily terminate the growth of the focal frond.

We conclude that Fucus vesiculosus is capable of inducing rapid resistance against grazing by its major herbivore Idotea baltica. The induction of resistance is highly local, diminishes after $10 \mathrm{~d}$, and does not spread within the algal individual. We thus suggest that it may be inefficient as a general defense against herbivory, but may benefit the alga by dispersing future damage within the individual and avoiding the breaking off of whole fronds. Whether such deterrence represents a defense adaptation against herbivory or arises as a side-effect of wound-healing metabolism cannot be concluded from the data and needs further research. In addition, the chemical substance behind the induction needs to be further clarified, as the deterrence is not derived from the alga's total phlorotannin concentration. Nutrient enhancement does not affect the inducible resistance of $F$. vesiculosus but reduces the long-term concentration of phlorotannins, which do not seem to play a role in induced defense.

Acknowledgements. We are grateful to the staff of the Archipelago Research Institute, University of Turku, for providing facilities. N. Heikkilä, A. Muola, K. Kostamo, O. Vesakoski and R. Leimu assisted with the fieldwork. J. Oja conducted the analyses of phlorotannins. We thank T. Korvenpää for analyzing the digital photographs. Nutrient levels in the water were determined at the Southwest Finland Regional Environmental Center. We thank 2 anonymous referees for constructive comments on the manuscript, as well as the PhD seminar of the Section of Ecology for discussions. Ellen Valle checked the language. Financial support was received from the Academy of Finland (project \#44086 and BIREME program) and from the Maj and Tor Nessling foundation (A.H.). 


\section{LITERATURE CITED}

Arnold TM, Targett NM (1998) Quantifying in situ rates of phlorotannin synthesis and polymerization in marine brown algae. J Chem Ecol 24:577-595

Arnold TM, Targett NM (2003) To grow and defend: lack of tradeoffs for brown algal phlorotannins. Oikos 100:406-408

Arnold TM, Tanner CE, Hatch WI (1995) Phenotypic variation in polyphenolic content of the tropical brown alga Lobophora variegata as a function of nitrogen availability. Mar Ecol Prog Ser 123:177-183

Arnold TM, Targett NM, Tanner CE, Hatch WI, Ferrari KE (2001) Evidence of methyl jasmonate-induced phlorotannin production in Fucus vesiculosus (Phaeophyceae). J Phycol 37:1026-1029

Boettcher AA, Targett NM (1993) Role of polyphenolic molecular size in reduction of assimilation efficiency in Xiphister mucosus. Ecology 74:891-903

Bryant JP, Chapin FS III, Klein DR (1983) Carbon/nutrient balance of boreal plants in relation to vertebrate herbivory. Oecologia 86:202-209

Carroll CR, Hoffman CA (1980) Chemical feeding deterrent mobilized in response to insect herbivory and counteradaptation by Epilacna tridecimnotata. Science 209: $414-416$

Clark CV, Harvell CD (1992) Inducible defenses and the allocation of resources: a minimal model. Am Nat 139:521-539

Cronin G, Hay ME (1996a) Induction of seaweed chemical defenses by amphipod grazing. Ecology 77:2287-2301

Cronin G, Hay ME (1996b) Effects of light and nutrient availability on the growth, secondary chemistry and resistance to herbivory of two brown seaweeds. Oikos 77:93-106

Deal MS, Hay ME, Wilson D, Fenical W (2003) Galactolipids rather than phlorotannins as herbivore deterrents in the brown seaweed Fucus vesiculosus. Oecologia 136:107-114

Diouris M, Floc'h JY (1984) Long-distance transport of ${ }^{14} \mathrm{C}$ labelled assimilates in the Fucales: directionality pathway and velocity. Mar Biol 78:199-204

Faberberg WR, Dawes CJ (1976) Studies on Sargassum. I. A light microscope examination of the wound regeneration process in mature stipes of $S$. filipendula. Am J Bot 63: $110-119$

Hammerström K, Dethier MN, Duggins DO (1998) Rapid phlorotannin induction in five Washington kelps. Mar Ecol Prog Ser 165:293-305

Harvell CD (1990) The ecology and evolution of inducible defenses. Q Rev Biol 65:323-340

Haukioja E (1982) Inducible defenses of white birch to a geometric defoliator Epirrita autumnata. In: Visser $\mathrm{JH}_{\text {, }}$ Minks AK (eds) Proceedings of 5th International Symposium on insect-plant relationships, Pudoc, Wageningen, The Netherlands, p 199-203

Hay ME (1996) Marine chemical ecology: what's known and what's next? J Exp Mar Biol Ecol 200:103-134

Hemmi A, Jormalainen V (2002) Nutrient enhancement increases performance of a marine herbivore via quality of its food alga. Ecology 83:1052-1064

Herms DA, Mattson WJ (1992) The dilemma of plants: to grow or defend. Q Rev Biol 67:283-335

Honkanen T, Jormalainen V (2002) Within-alga integration and compensation: effects of simulated herbivory on growth and reproduction of the brown alga Fucus vesiculosus. Int J Plant Sci 163:815-823

Ilvessalo H, Tuomi J (1989) Nutrient availability and accumulation of phenolic compounds in the brown alga Fucus vesiculosus. Mar Biol 101:115-119

Jormalainen V, Merilaita S, Tuomi J (1995) Differential preda- tion on sexes affects colour polymorphism of the isopod Idotea baltica (Pallas). Biol J Linn Soc 55:45-68

Jormalainen V, Honkanen T, Heikkilä N (2001a) Feeding preferences and performance of a marine isopod on seaweed hosts - cost of habitat specialization. Mar Ecol Prog Ser 220:219-230

Jormalainen V, Honkanen T, Mäkinen A, Hemmi A, Vesakoski O (2001b) Why does herbivore sex matter? Sexual differences in utilization of Fucus vesiculosus by the isopod Idotea baltica. Oikos 93:77-86

Kangas P, Autio H, Hällfors G, Luther H, Niemi A, Salemaa H (1982) A general model of the decline of Fucus vesiculosus at Tvärminne, south coast of Finland in 1977-81. Acta Bot Fenn 118:1-27

Karban R, Baldwin IT (1997) Induced responses to herbivory. University of Chicago Press, Chicago, IL

Karban R, Myers JH (1989) Induced plant responses to herbivory. Annu Rev Ecol Syst 20:331-348

Karban R, Agrawal AA, Mangel M (1997) The benefits of induced defenses against herbivores. Ecology 78: 1351-1355

Koricheva J (2002) Meta-analysis of sources of variation in fitness costs of plant antiherbivore defenses. Ecology 83: $176-190$

Koroleff F (1976) Determination of nutrients. In: Grasshof K (ed) Methods of seawater analysis. Verlag Chemie, Weinheim, p 117-182

Lehvo A, Back S, Kiirikki M (2001) Growth of Fucus vesiculosus L. (Phaeophyta) in the northern Baltic proper: energy and nitrogen storage in seasonal environment. Bot Mar 44:345-350

Lowell RB, Markham JH, Mann H (1991) Herbivore-like damage induces increased strength and toughness in a seaweed. Proc R Soc Lond Ser B 243:31-38

Lüning K (1990) Seaweeds. Their environment, biogeography and ecophysiology. John Wiley \& Sons, New York

Marquis RJ (1992) A bite is a bite is a bite? Constraints on response to folivory in Piper arieianum (Piperaceae). Ecology 73:143-152

Moss B (1983) Sieve elements in the Fucales. New Phytol 93:433-437

Nurmi K, Ossipov V, Haukioja E, Pihlaja K (1996) Variation of total phenolic content. J Chem Ecol 22:2023-2040

Pavia H, Åberg P (1996) Spatial variation in polyphenolic content of Ascophyllum nodosum (Fucales, Phaeophyta). Hydrobiologia 326-7:119-203

Pavia H, Toth GB (2000) Inducible chemical resistance to herbivory in the brown seaweed Ascophyllum nodosum. Ecology 81:3212-3225

Pavia H, Cervin G, Lindgren A, Åberg P (1997) Effects of UV-B radiation and simulated herbivory on phlorotannins in the brown alga Ascophyllum nodosum. Mar Ecol Prog Ser 157:139-146

Pavia H, Toth G, Åberg P (1999) Trade-offs between phlorotannin production and annual growth in natural populations of the brown seaweed Ascophyllum nodosum. J Ecol 87:761-771

Pawlik JR (1992) Chemical ecology of the settlement of benthic marine invertebrates. Oceanogr Mar Biol Annu Rev 30:273-335

Peckol P, Krane JM, Yates JL (1996) Interactive effects of inducible defense and resource availability on phlorotannins in the north Atlantic brown alga Fucus vesiculosus. Mar Ecol Prog Ser 138:209-217

Pfister CA (1992) Costs of reproduction in an intertidal kelp: patterns of allocation and life history consequences. Ecology 73:1586-1596 
Ragan MA, Glombitza KW (1986) Phlorotannins, brown algal polyphenols. Prog Phycol Res 4:130-241

Rhoades DF (1979) Evolution of plant chemical defense against herbivores. In: Rosenthal GA, Janzen DH (eds) Herbivores: their interaction with secondary plant metabolites. Academic Press, New York, p 3-54

Salemaa H (1979) Ecology of Idotea spp. (Isopoda) in the Northern Baltic. Ophelia 18:133-150

Salemaa H (1987) Herbivory and microhabitat preferences of Idotea spp. (Isopoda) in the northern Baltic Sea. Ophelia 27:1-15

SAS Institute (2000) SAS/STAT user's guide: statistics version 8.01. SAS Institute, Cary, NC

Schaffelke B, Evers D, Walhorn A (1995) Selective grazing of the isopod Idotea baltica between Fucus evanescens and F. vesiculosus from Kiel Fjord (western Baltic). Mar Biol 124:215-218

Schmitt TM, Hay ME, Lindqvist N (1995) Constraints on chemically mediated coevolution: multiple functions of seaweed secondary metabolites. Ecology 6:107-113

Schoenwaelder MEA (2002) The occurrence and cellular significance of physodes in brown algae. Phycologia 41: 125-139

Steinberg PD (1994) Lack of short-term induction of phlorotannins in the Australian brown algae Ecklonia radi-

Editorial responsibility: Victor de Jonge (Contributing Editor), Haren, The Netherlands ata and Sargassum vestitum. Mar Ecol Prog Ser 112: 129-133

Steinberg PD (1995) Seasonal variation in the relationship between growth rate and phlorotannin production in the kelp Ecklonia radiata. Oecologia 102:169-173

Targett NM (2001) Impact of environmental changes on production of brown algal phlorotannins. J Phycol 37:48

Targett NM, Arnold TM (1998) Predicting the effects of brown algal phlorotannins on marine herbivores in tropical and temperate oceans. J Phycol 34:195-205

Tollrian R, Harvell CD (eds) (1999) The ecology and evolution of inducible defenses. Princeton University Press, Princeton, NJ

Toth GB, Pavia H (2000) Water-borne cues induce chemical defense in a marine alga (Ascophyllum nodosum). Proc Natl Acad Sci USA 97:14418-14420

Toth GB, Pavia H (2002) Lack of phlorotannin induction in the kelp Laminaria hyperborea in response to grazing by two gastropod herbivores. Mar Biol 140:403-409

Van Alstyne KL (1988) Herbivore grazing increases polyphenolic defenses in the intertidal brown alga Fucus distichus. Ecology 69:655-663

Yates JL, Peckol P (1993) Effects of nutrient availability and herbivory on polyphenolics in the seaweed Fucus vesiculosus. Ecology 74:1757-1766

Submitted: February 5, 2003; Accepted: January 31, 2004

Proofs received from author(s): May 28, 2004 